\title{
Measuring the breath of life
}

So long as men can breathe, or eyes can see,

So long lives this and this gives life to thee.

Sonnet 23, William Shakespeare

The inability to breathe freely and clearly is a major source of concern to patients and a common symptom in many sinonasal conditions ${ }^{(1)}$. There are of course some semantic differences between terms such as 'obstruction', congestion' and 'blockage', which have to be clarified when taking a clinical history as the presence of inflammation may produce the sensation of congestion without actually being associated with mechanical obstruction to airflow ${ }^{(2)}$. Notwthstanding this, nasal obstruction is the commonest complaint in chronic rhinosinusitis with and without nasal polyps ${ }^{(3)}$ and is a major feature of conditions from the common cold and acute bacterial rhinosinusitis to allergic and non-allergic rhinitis, septal deformity or a tumour. Paradoxically, many people, myself included, go through life largely oblivious to a significant septal deflection. It therefore begs the question as to why an individual with a long-standing anatomical variant such as this, suddenly presents with the symptom of nasal blockage and it is important that we do not simply focus on the septum (or turbinate) but rather ask ourselves 'Why now?' instead of simply listing the patient for septal surgery.

Much discussion and many papers have been published on the difficulties of correlating this clinical complaint with objective measures such as rhinomanometry ${ }^{(4-6)}$ but it is hardly surprising that patients who have objective evidence of nasal obstruction do significantly better after septal surgery than those who do not have a genuinely blocked nose ${ }^{(7)}$. Yet patients are frequently listed for surgery to both the septum and turbinates without any objective assessment of their airway being performed. In the UK each year around 23,000 septal operations are performed (out of a population of $\sim 63$ million) and 6-7,000 turbinate reductions though the numbers have been slowly decreasing since 2000. Only a very small minority of these will have had any pre-operative objective assessment of their airway.

It is unlikely that any of us would insert a grommet into an ear drum without a pre-operative audiogram/tympanogram but the same rigour is not applied to the nose in many parts of the world. There are numerous reasons for this, not least the dynamic nature of the nasal cavity subject to frequent changes in response to the nasal cycle, environmental factors and various reflexes. In addition finding a test which has a reasonable inter- and intra-individual coefficient of variation has proved challenging but this does not mean we have to be defeatist and I am delighted that so many of this issue's authors have taken up the challenge to apply objective measures to a variety of clinical situations ${ }^{(8-10)}$.

A range of airway tests are available, which will complement our endoscopic findings, including nasal peak flow, rhinomanometry and acoustic rhinometry. Of these peak nasal inspiratory flow (PNIF) is the cheapest, easiest and quickest to perform but suffers from the disadvantages that the forced inspiration may produce alar collapse and significant lower respiratory tract disease can compromise inspiratory effort. On the plus side, it has good repeatability and can be used by patients at home, in the same way that oral-pulmonary peak flow can be undertaken ${ }^{(11)}$. Originally both sides of the nose were measured together but unilateral assessment is now possible ${ }^{(12,13)}$. PNIF has been shown to correlate reasonably well with rhinomanometry ${ }^{(14)}$ and normative data has now been established in both adults ${ }^{(15,16)}$ and children ${ }^{(17-19)}$ making this is an excellent option to compare pre- and post-operative outcomes after septal and turbinate surgery ${ }^{(16)}$, in quantifying a nasal histamine challenge ${ }^{(20)}$ or the therapeutic response in allergic rhinitis ${ }^{(10)}$. PNIF may also enable a distinction to be drawn between obstruction due to decongestable soft tissue and structural deformity of bone or cartilage ${ }^{(9)}$ thereby assisting in the appropriate selection of surgical procedure.

The diagnosis and treatment of alar collapse can be quite a challenge ${ }^{(21)}$ but this can also be confirmed when PNIF is compared with acoustic rhinometry. However, it is interesting to see that this can also be determined using a simple scoring system which has good inter-rater agreement amongst clinicians ${ }^{(22)}$.

The anatomy of the nose and sinuses remains a perennial favourite for investigation as evidenced by other papers in this issue ${ }^{(23,24)}$ and I would like to draw your attention again to our most recent supplement, the European Position Paper on the Anatomical Terminology of the Internal Nose and Paranasal Sinuses, which is the product of an indepth re-examination of all the terminology used during endoscopic sinonasal surgery ${ }^{(25)}$. This proved a learning experience for all concerned as we 
discovered areas that required clarification, even in a group of experienced endoscopic surgeons. The full document can be downloaded for free from the Rhinology website: (www.rhinologyjournal.com).

Finally another new benefit for readers is the offer of an app called 'Rhinology', which will allow you to access the journal whereever and whenever you wish from your smart phone and tablet. Its available for iOS and Android in the respective AppStores. A subscription to Rhinology gives access to full papers.

I look forward to seeing you all in Amsterdam, in the next few weeks, when the 25th Congress of ERS will be held in conjunction with the 33rd ISIAN and seems likely to be one of the biggest and best yet.

\section{References}

1. Rhee J, Book D, Burzynski M, Smith T. Quality of life assessment in nasal airway obstruction. Laryngoscope. 2003; 113: 1118-1122.

2. Kjaergaard T, Cvancarova M, Steinsvag S. Does nasal obstruction mean that the nose is obstructed? Laryngoscope. 2008; 118: 1476-1481.

3. Browne JP, Hopkins C, Slack R, et al. Healthrelated quality of life after polypectomy with and without additional surgery. Laryngoscope. 2006; 116: 297-302.

4. Jones A, Viani L, Phillips D, et al. The objective assessment of nasal patency. Clin Otolaryngol. 1991; 16: 206-211.

5. Roithmann R, Cole P, Chapnik J, et al Acoustic rhinometry, rhinomanometry and the sensation of nasal patency:: a correlative study. J Otolaryngol. 1994; 23: 454-458.

6. Andre R, Vuyk H, Ahmed A, et al. Correlation between subjective and objective evaluation of the nasal airway. Clin Otolaryngol. 2009; 34: 518-525.

7. Holmstrom M. The use of objective measures in selecting patients for septal surgery. Rhinology. 2010; 48: 387-393.

8. Balikci HH, Gurdal MM. Use of peak nasal inspiratory flowmetry and nasal decongestant to evaluate outcome of septoplasty with radiofrequency coblation of the inferior turbinate. Rhinology. 2014; 52: 112-115.

9. Chin D, Marcells G, Malek J, Pratt E, Sacks R, Snidvongs K, Harvey R. Nasal peak inspiratory flow (NPIF) as a diagnostic tool for differentiating decongestable from structural nasal obstruction. Rhinology. 2014; 52: 116121.

10. de Souza Campos Fernandes S, Ribeiro De Andrade C, da Cunha Ibiapina C. Application of Peak Nasal Inspiratory Flow reference values in the treatment of allergic rhinitis. Rhinology. 2014; 52: 133-136.

11. Starling-Schwanz R, Peake H, Salome C, et al. Repeatability of peak nasal inspiratory flow measurements and utility for assessing the severity of rhinitis. Allergy. 2005; 60: 795-800.

12. Ottaviano H, Scadding G, Scarpa B, et al. Unilateral peak nasal inspiratory flow, normal values in adult population. Rhinology. 2012; 50: 386-392

13. Ottaviano G, Lund VJ, Nardello E, et al. Comparison between unilateral PNIF and rhinomanometry inn healthy and obstructed noses. Rhinology. 2014; 52: 25-30.

14. Holmstrom M, Scadding G, Lund VJ, et al. Assessment of nasal obstruction. A comparison between rhinomanometry and nasal inspiratory peak flow. Rhinology. 1990; 28: 191-196.

15. Ottaviano G, Scadding G, Coles S, Lund VJ. Peak nasal inspiratory flow; normal range in adult population. Rhinology. 2006; 44: 32-35.

16. Ozkul H, Balikci H, Gurdal M, et al. Normal range of inspiratory flow and its role in nasal septal surgery. Carniofac Surg. 2013; 24: 900902.

17. Papchristou A, Bourli E, Aivazi D, et al. Normal peak nasal inspiratory flow rate values in Greek children and adolescents. Hippokratia. 2008; 12: 94-97.
18. Ibiapina C, Andrade C, Camargos P, et al. Reference values for peak nasal inspiratory flow in children and adolescents in Brazil. Rhinology. 2011; 49: 304-308.

19. Van Spronsen E, Ebbens F, Fokkens WJ. Normal peak nasal inspiratory flow rate values in healthy children between 6 and 11 years in the Netherlands. Rhinology. 2012; 50: $22-25$

20. Wilson A, Sims E, Robb F, et al. Peak inspiratory flow rate is more sensitive than acoustic rhinometry or rhinomanometry in detecting corticosteroid response with nasal histamine challenge. Rhinology. 2003; 41: 16-20.

21. Wittkopf M, Wittkopf J, Ries W. The diagnosis and treatment of nasal valve collapse. Curr Opin Otolaryngol Head Neck Surg. 2008; 16: 10-13.

22. Poirrier AL, Ahluwalia S, Kwame I, Chau H, Bentley M, Andrews P. External nasal valve collapse: validation of novel outcome measurement tool. Rhinology. 2014; 52:

23. Havel M, Ertl L, Bauer D, Schuster M, Stelter K, Sundberg J. Resonator properties of paranasal sinuses: preliminary results of an anatomical study. Rhinology. 2014; 52: 178-182.

24. Tekke NS, Alkan Z, Yigit O, et al. Importance of nasal septal cartilage perichondrium for septum strength mechanics: a cadaveric study. Rhinology. 2014; 52: 167-171.

25. Lund V, Stammberger H, Fokkens W et al. European Position Paper on the Anatomical Terminology of the Internal Nose and Paranasal Sinuses. Rhinology. 2014 Supplement 24: 1-38.
Valerie J. Lund, Co-Editor in Chief London, United Kingdom

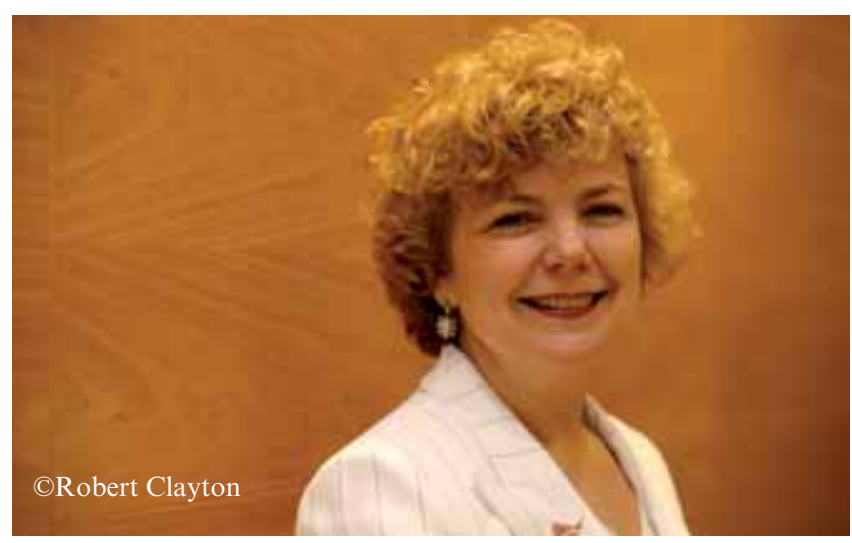

